\title{
Diabetes Insipidus in Craniopharyngioma after Ventriculoperitoneal (VP) Shunt Surgery - a case report
}

Chen Shen, Foundation Year 1 Doctor, Department of Endocrinology, Pilgrim Hospital, Boston

\section{Introduction}

Craniopharyngioma is a rare and benign type of tumour derived from squamous cell nests of the primitive Rathke's pouch of the pituitary gland. Commonly present in childhood, it is also found in adults in their 50s and 60s. People may initially present with vision disturbance, usually bitemporal inferior quadrantanopia, progressing to bitemporal hemianopsia as the tumour grows and compresses on the optic chiasm. Although a slow-growing tumour, both the disorder and therapy associated complex neuroendocrine symptoms, especially salt disorders, can bring considerable challenges to subsequent care.

\section{Case Study}

A 64-year-old man with a known heterogeneous craniopharyngioma measuring $2.9 \mathrm{~cm}$ (transverse) $\times 3.45$ $\mathrm{cm}$ (craniocaudal) $\times 3.15 \mathrm{~cm}$ (anteroposterior), was referred to A\&E by his GP, 15 months after VP shunt procedure for hydrocephalus.

At the time of admission, there has been a six months' history of persistent and worsening hypernatremia. Clinically euvolaemic, he also presented with polydipsia, increased confusion and irritability on the background of gradual cognitive decline. The tumour has also rendered him partially blind and incontinent. Despite difficulty in monitoring fluid balance accurately due to patient's inability to keep the catheter in situ, polyuria was evident.

Paired urine and serum osmolality test confirmed cranial diabetes insipidus. Hypernatremia responded well to desmopressin (DDAVP) therapy and long-term desmopressin is required to maintain a stable electrolyte balance.

$\begin{array}{ll}\text { Urine } & \text { Serum } \\ \begin{array}{l}\text { Random urine sodium } 42 \mathrm{mmol} / \mathrm{L} \\ \text { Random urine potassium } 11\end{array} & \text { Sodium } 155 \mathrm{mmol} / \mathrm{L} \\ \mathrm{mmol} / \mathrm{L} & \text { Potassium } 3.6 \mathrm{mmol} / \mathrm{L} \\ \text { Random urine urea } 46 \mathrm{mmol} / \mathrm{L} & \text { Urea } 3 \mathrm{mmol} / \mathrm{L} \\ \text { Random creatinine } 2.8 \mathrm{mmol} / \mathrm{L} & \text { Creatinine } 87 \mu \mathrm{mol} / \mathrm{L} \quad \text { eGFR } 81 \\ \text { Osmolality } 201 \mathrm{mosmol} / \mathrm{kg} & \text { Osmolality } 314 \mathrm{mmol} / \mathrm{kg}(>300) \\ & \text { Glucose } 5.3 \mathrm{mmol} / \mathrm{L} \\ & \text { HbA1c } 40 \mathrm{mmol} / \mathrm{mol} \\ & \text { Satisfactory Short Synacthen Test } \\ & \\ & \text { TSH: } 0.09 \mathrm{mU} / \mathrm{L}(\downarrow) \\ & \text { Free T4: } 13.2 \mathrm{pmol} / \mathrm{L} \\ & \text { Free T3: } 3.85 \mathrm{pmol} / \mathrm{L} \\ & \text { Prolactin: } 4 \mathrm{mU} / \mathrm{L}(\downarrow) \\ & \text { Testosterone: } 0.3 \mathrm{nmol} / \mathrm{L}(\downarrow) \\ & \text { IGF-1: } 4.9 \mathrm{nmol} / \mathrm{L}(\downarrow)\end{array}$

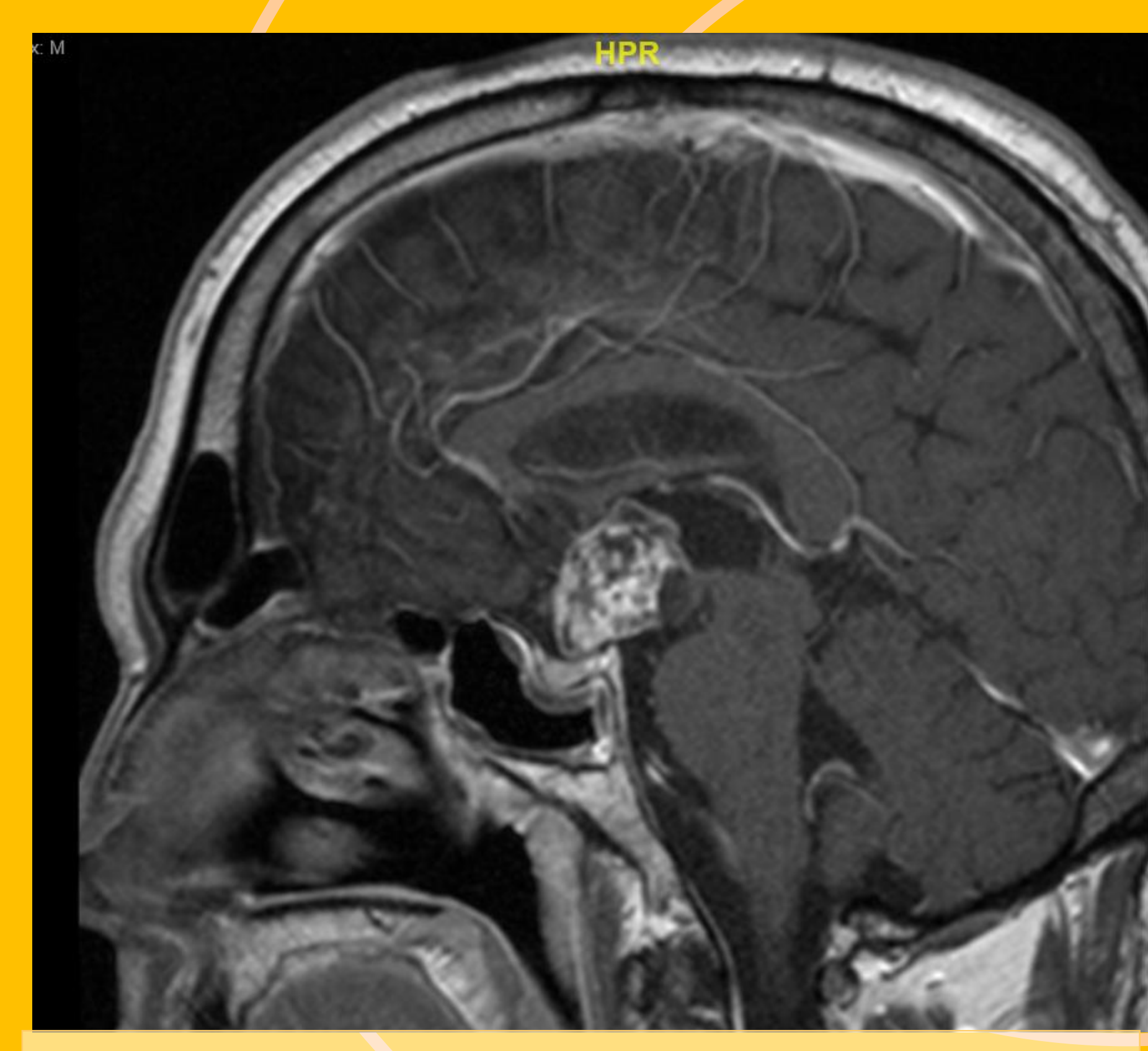

At the time of diagnosis

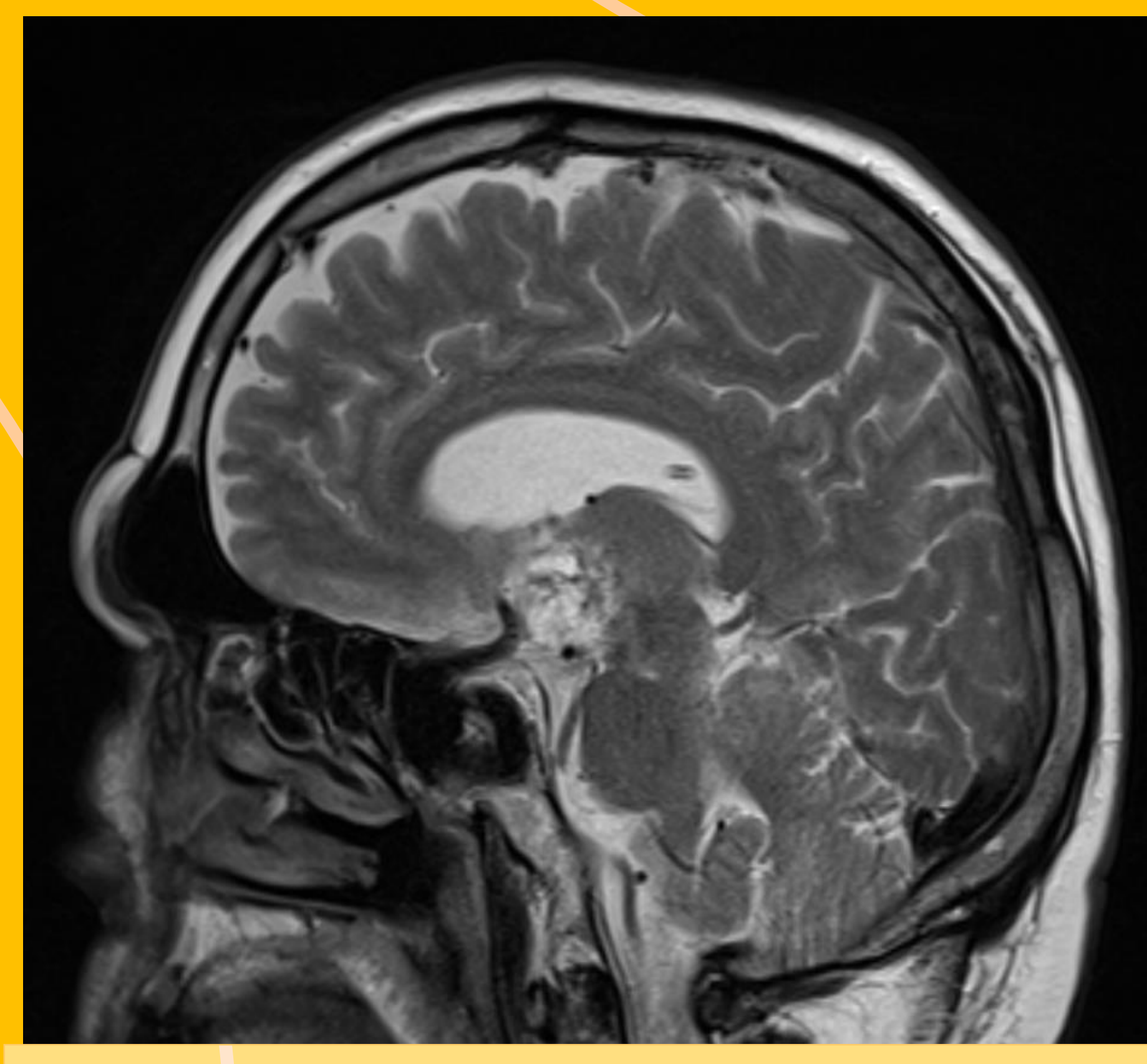

8 months post-VP shunt

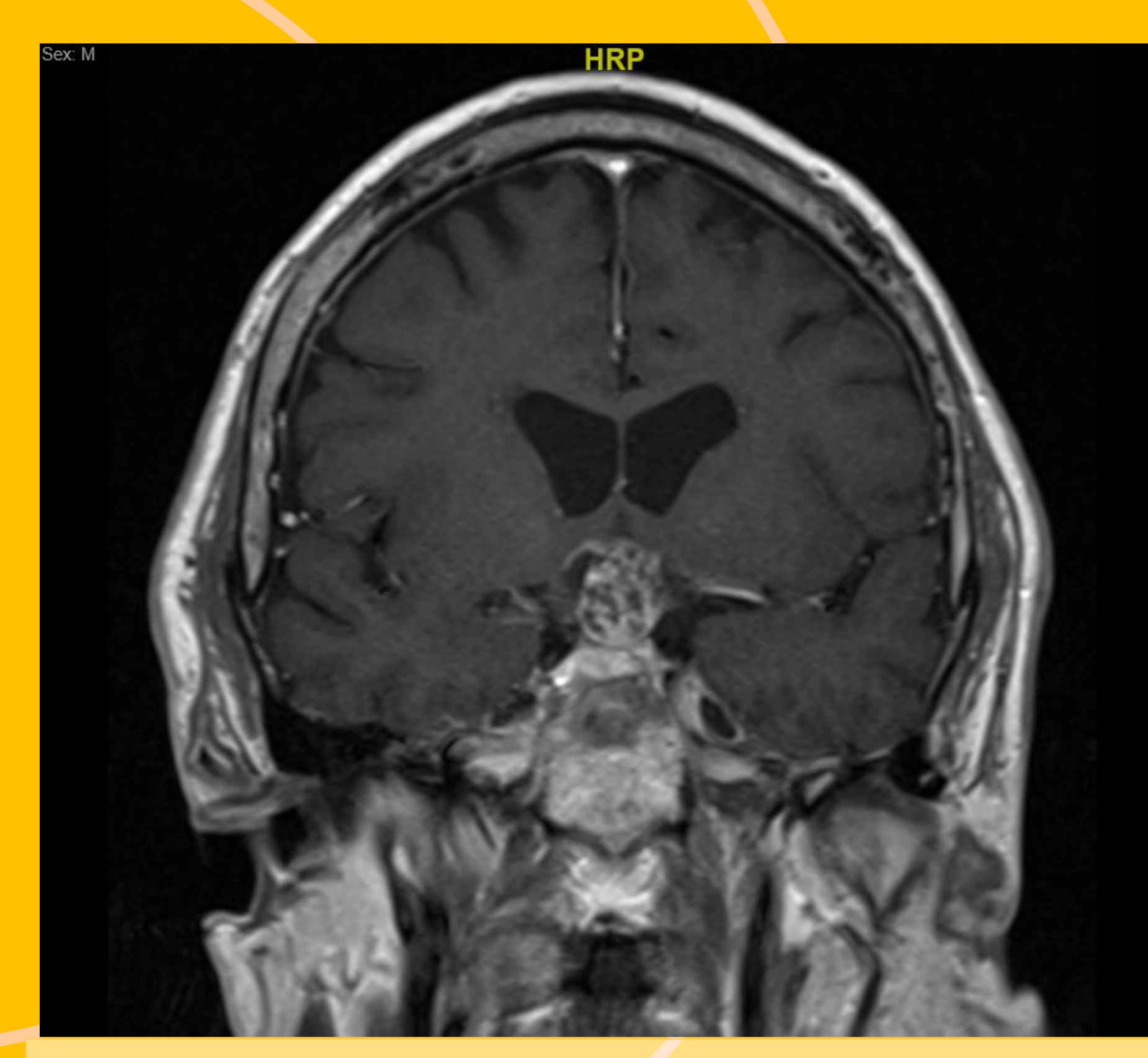

At the time of diagnosis

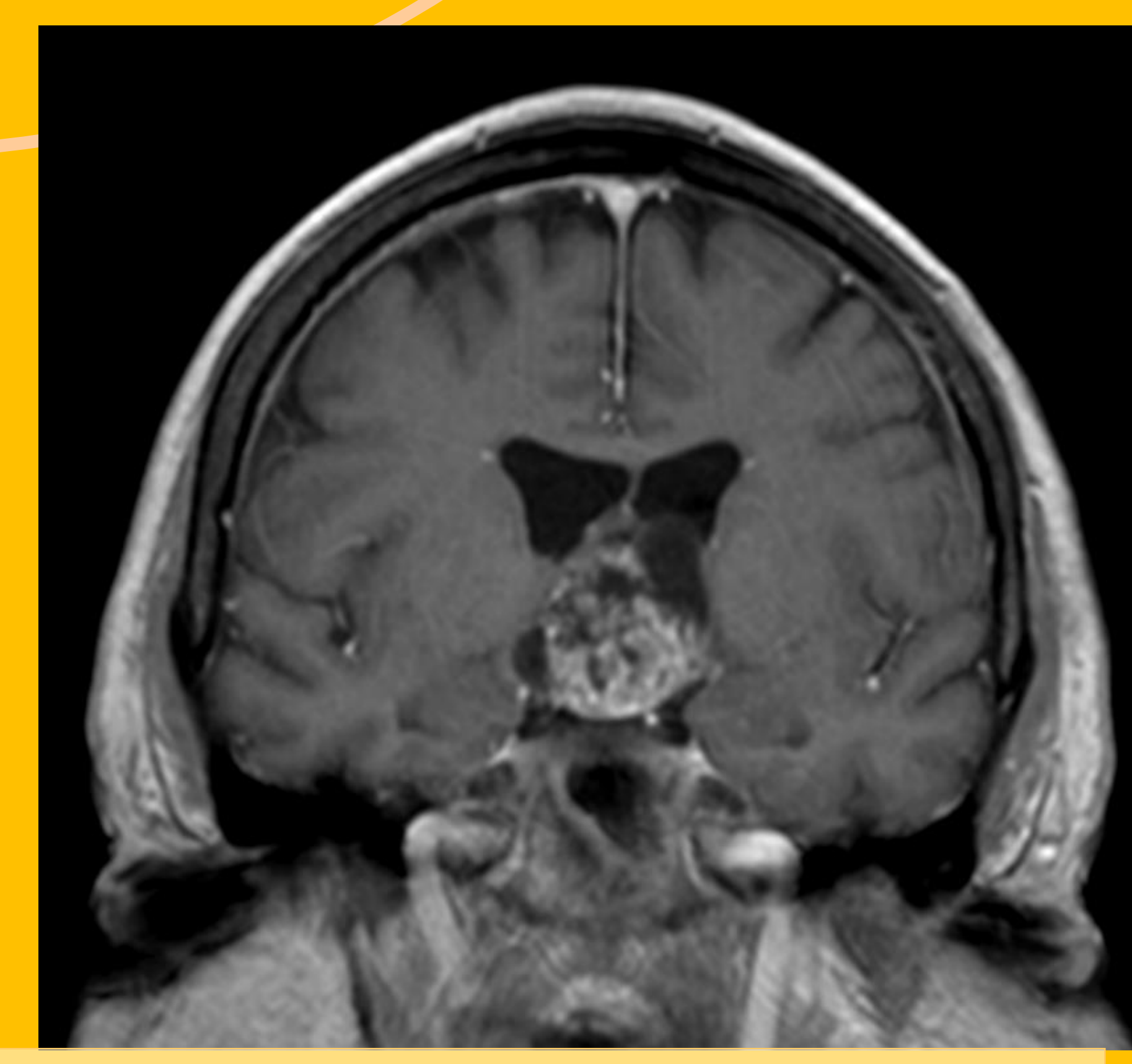

8 months post-VP shunt

\section{Discussion \& Conclusions}

Cranial diabetes insipidus has been reported in multiple literature to be significantly more prevalent in those managed with surgery. It is permanent only if there is bilateral degeneration of more than $80 \%$ of the arginine vasopressin (AVP)secreting neurons in the supraoptic and paraventricular hypothalamic nucleil. This case illustrates that although the tumour itself was not resected, associated intracranial intervention in the area may also result a similar manifestation.

All clinicians should raise the index of suspicion of cranial diabetes insipidus in craniopharyngioma patients presenting with hypernatremia. Recognition of diabetes insipidus is critical to institution of appropriate therapy and prevention of life-threatening electrolyte disturbances.

\footnotetext{
References: Garrè ML, Cama A .Craniopharyngioma: modern concepts in pathogenesis and treatment. Curr. Opin. Pediatr. 2007 19 (4): 471 -9 Edate S, Albanese A. Management of electrolyte and fluid disorders after brain surgery for pituitary/suprasellar tumours. Horm Res Paediatr. 2015;83(5):293-301. Mark J. Hannon Francis M. Finucane Mark Sherlock Amar AghaChristopher J. Thompson. Disorders of Water Homeostasis in Neurosurgical Patients. The Journal of Clinical 1 lume 97, Issue 1 May 2012, Pages 1423-1433 